\section{What is already known on this topic}

Considerable overlap exists between Alzheimer's disease and vascular dementia

Vascular risk factors may be involved in the causation of both conditions

Spontaneous cerebral emboli are associated with increased risk of stroke and cognitive impairment in patients having carotid or cardiac surgery

\section{What this study adds}

Spontaneous cerebral emboli are significantly associated with both Alzheimer's disease and vascular dementia and may be involved in the pathophysiology of both conditions

Spontaneous cerebral emboli may represent potentially preventable or treatable cause of both types of dementia

Ethical approval: Local research ethics committees in Manchester and Stockport: South and North Manchester LREC reference SOU/98/132; Central Manchester LREC reference CEN/00/027/CA; Stockport LREC reference EE/SR/ MREC2029.

1 Skoog I, Kalaria RN, Breteler MMB. Vascular factors and Alzheimer disease. Alzheimer Dis Assoc Disord 1999;13:S106-14.

2 Hofman A, Ott A, Breteler MM, Bots ML, Slooter AJ, van Harskamp F Atherosclerosis, apolipoprotein $\mathrm{E}$, and prevalence of dementia and Alzheimer's disease in the Rotterdam study. Lancet 1997;349:151-4.

3 Sliwka U, Job FP, Wissuwa D, Diehl RR, Flachskampf FA, Hanrath P, et al. Occurrence of transcranial Doppler high-intensity transient signals in patients with potential cardiac sources of embolism: a prospective study. Patients with potential cardi

4 Anzola GP. Clinical impact of patent foramen ovale diagnosis with transcranial Doppler. Eur J Ultrasound 2002;16:11-20.

5 Ott A, Breteler MM, de Bruyne MC, van Harskamp F, Grobbee DE, Hof man A. Atrial fibrillation and dementia in a population-based study. Stroke 1997;28:316-21.
6 Lechat P, Mas JL, Lascault G. Prevalence of patent foramen ovale in patients with stroke. N Engl J Med 1988;318:1148-59.

7 Webster MW, Chancellor AM, Smith HJ, Swift DL, Sharpe DN, Bass NM, et al. Patent foramen ovale in young stroke patients. Lancet 1988;ii:11-2.

8 Riding G, Rao S, Hutchinson S, Kilic J, Lovell M, McCollum C. Cerebra emboli during hip and knee replacement: the role of venous to arterial shunting [abstract]. BrJ Surg 2001;88:745.

9 Meier B, Lock JE. Contemporary management of patent foramen ovale Circulation 2003;107:5-9.

10 Sastry S, MacNab A, Daly K, Ray SG, McCollum CN. Transcranial Doppler or transoesophageal echocardiography for the detection of venous-to-arterial circulation shunts [abstract]. Heart 2002;88(suppl IV):32.

11 Purandare N, Welsh S, Hutchinson S, Riding G, Burns A, McCollum C Cerebral emboli and paradoxical embolisation in dementia: a pilot study. Int J Geriatr Psychiatry 2005;20:12-6.

12 Folstein MF, Folstein SE, McHugh PR. Mini-mental state: a practical method for grading the cognitive state of patients for the clinician. Psychiatry Res 1975;12:189-98.

13 McKhann G, Drachman D, Folstein M, Katzman R, Price D, Stadlan EM Clinical diagnosis of Alzheimer's disease: report of the NINCDS-ADRDA Work Group under the auspices of Department of Health and Human Services Task Force on Alzheimer's Disease. Neurology 1984:34:939-44.

14 Roman GC, Tatemichi TK, Erkinjuntti T, Cummings JL, Masdeu JC, Garcia JH, et al. Vascular dementia: diagnostic criteria for research studies. Report of the NINDS-AIREN International Workshop. Neurology 1993;43:250-60.

15 Consensus Committee of the Ninth International Cerebral Hemodynamic Symposium. Basic identification criteria of Doppler microembolic signals. Stroke 1995;26:1123.

16 Sidhu PS, Allen PL. Ultrasound assessment of internal carotid artery stenosis. Clin Radiol 1997;52:654-8.

17 Di Tullio M, Sacco RL, Venketasubramanian N, Sherman D, Mohr JP, Homma S. Comparison of diagnostic techniques for the detection of a patent foramen ovale in stroke patients. Stroke 1993;24:1020-4.

18 Nygren AT, Jogestrand T. Detection of patent foramen ovale by transcranial Doppler and carotid duplex ultrasonography: a comparison with transoesophageal echocardiography. Clin Physiol 1998;18:327-30.

19 Droste DW, Silling K, Stypmann J, Grude M, Kemeny V, Wichter T, et al Contrast transcranial doppler ultrasound in the detection of right-to-left shunts: time window and threshold in microbubble numbers. Stroke shunts: time win $2000 ; 31: 1640-5$.

20 Stewart R, Prince M, Mann A. Vascular risk factors and Alzheimer's disease. Aust N Z J Psychiatry 1999;33:809-13

21 Hutchinson S, Riding G, Coull S, McCollum CN. Are spontaneous cerebral microemboli consistent in carotid disease? Stroke 2002;33:685-8.

22 Stork JL, Kimura K, Levi CR, Chambers BR, Abbott AL, Donnan GA Source of microembolic signals in patients with high-grade carotid stenosis. Stroke 2002;33:2014-8.

23 Meier B. Closure of patent foramen ovale: technique, pitfalls, complications, and follow up. Heart 2005;91:444-8.

(Accepted 7 March 2006)

doi 10.1136/bmj.38814.696493.AE
National Institute of Public Health, Øste Farimagsgade 5A

1399 DK,

Copenhagen,

Denmark

Maren Johanne

Heilskov Rytter

medical student

Anne-Lene

Kjældgaard

medical student

Henrik

Brønnum-Hansen

senior researcher

Karin

Helweg-Larsen

senior researcher

Correspondence to:

K Helweg-Larsen

khl@niph.dk

BMJ 2006;332:1122-4

\title{
Effects of armed conflict on access to emergency health care in Palestinian West Bank: systematic collection of data in emergency departments
}

Maren Johanne Heilskov Rytter, Anne-Lene Kjældgaard, Henrik Brønnum-Hansen,

Karin Helweg-Larsen

\begin{abstract}
Objective To assess the impact of restrictions in access to hospital services imposed on the civilian population during the armed conflict in the Palestinian territories occupied by Israel.

Design Consecutive registration of demographic and medical data, with information about transportation time, delay in access to hospital, and course of hospital contact.

Setting Three hospital emergency departments in Bethlehem and Nablus, in the occupied Palestinian West Bank, during one week in each hospital. Participants All patients seeking health care in the three hospitals during the study period.
\end{abstract}

Results A total of 394 of the 2228 emergency department contacts reported being delayed at checkpoints or by detours on their way to the emergency department. Hospital admission was significantly more common for these patients: $32 \%$ $(\mathrm{n}=125)$ compared with $13 \%(\mathrm{n}=205)$ among those who were not delayed.

Conclusion 18\% of the emergency department contacts were delayed because of the occupation. The higher hospital admission rate in this group suggests that restrictions in access to hospital services influence the severity of the medical conditions presented.

This article was posted on bmj.com on 3 April 2006: http://bmi.com/cgi/ doi/10.1136/bmj.38793.695081.AE 


\section{Introduction}

Armed conflict affects public health in various ways. In the Palestinian territories occupied by Israel, tight restrictions have been imposed on the population. Towns and villages are encircled by military checkpoints, making passage difficult, unpredictable, and occasionally impossible.

The World Health Organization recommends collection of data in emergency departments as a tool to assess the health consequences of armed conflicts. ${ }^{1}$ Through systematic data collection, we analysed the extent of restrictions in access to hospital services and its impact on the frequency of admission to hospital.

\section{Methods}

We included all emergency department contacts during eight days and nights in January 2005 in one hospital in Bethlehem and two hospitals in Nablus in the occupied Palestinian West Bank. A registration form was filled out for each patient, including details of age, sex, residence, civil status, reason for hospital contact, main diagnosis, causes of injuries, and course of hospital contact. We obtained information about each patient's distance travelled to the hospital, transportation time, means of transportation, and any delay. We categorised self reported delay as conflict related delay (checkpoints, detour, and curfew) and other delay (traffic jam and other reasons). For each patient, we calculated speed of travel on the basis of transportation time and distance.

\section{Results}

Among all 2228 people who contacted the three hospitals during the study period, 394 (18\%) reported

Number (percentage) of patients delayed or not, by course of hospital contact

\begin{tabular}{|c|c|c|c|c|}
\hline \multirow[b]{2}{*}{$\begin{array}{l}\text { Hospital and } \\
\text { delay }\end{array}$} & \multicolumn{4}{|c|}{ Course of hospital contact } \\
\hline & $\begin{array}{l}\text { Discharged to } \\
\text { home }\end{array}$ & $\begin{array}{l}\text { Admitted or } \\
\text { referred to } \\
\text { other hospital }\end{array}$ & $\begin{array}{l}\text { Dead or not } \\
\text { stated }\end{array}$ & All \\
\hline \multicolumn{5}{|c|}{ Al Watani, Nablus } \\
\hline $\begin{array}{l}\text { Conflict related } \\
\text { delay }\end{array}$ & $53(44)$ & $58(48)$ & $10(8)$ & 121 \\
\hline Other delay & $72(76)$ & $20(21)$ & $3(3)$ & 95 \\
\hline No delay & $706(80)$ & $122(14)$ & $52(6)$ & 880 \\
\hline All & 831 (76) & $200(18)$ & $65(6)$ & 1096 \\
\hline \multicolumn{5}{|l|}{ Rafidya, Nablus } \\
\hline $\begin{array}{l}\text { Conflict related } \\
\text { delay }\end{array}$ & $100(72)$ & $31(22)$ & $7(5)$ & 138 \\
\hline Other delay & $61(94)$ & $4(6)$ & 0 & 65 \\
\hline No delay & $243(90)$ & $16(6)$ & $12(4)$ & 271 \\
\hline All & $404(85)$ & $51(11)$ & $19(4)$ & 474 \\
\hline \multicolumn{5}{|c|}{ King Hussein Hospital, Bethlehem } \\
\hline $\begin{array}{l}\text { Conflict related } \\
\text { delay }\end{array}$ & $88(65)$ & $36(27)$ & $11(8)$ & 135 \\
\hline Other delay & $65(72)$ & $20(22)$ & $5(6)$ & 90 \\
\hline No delay & 341 (79) & $67(15)$ & $25(6)$ & 433 \\
\hline$\overline{\text { All }}$ & 494 (75) & $123(19)$ & $41(6)$ & 658 \\
\hline \multicolumn{5}{|l|}{ All hospitals } \\
\hline $\begin{array}{l}\text { Conflict related } \\
\text { delay }\end{array}$ & 241 (61) & $125(32)$ & $28(7)$ & 394 \\
\hline Other delay & $198(79)$ & $44(18)$ & $8(3)$ & 250 \\
\hline No delay & $1290(81)$ & $205(13)$ & $89(6)$ & 1584 \\
\hline All & $1729(78)$ & $374(17)$ & $125(6)$ & 2228 \\
\hline
\end{tabular}

\section{What is already known on this topic}

Research in the health consequences of armed conflicts is still in its infancy

The occupation of Palestine includes movement restrictions that may influence access to health care, but the size of this problem is not known

\section{What this study adds}

Data collection among emergency department contacts showed that patients delayed by the Israeli occupation were more likely to be admitted to hospital than were other patients

being delayed at checkpoints or by detours. Admission to hospital was more common among old and very young patients than among young and middle aged patients. In all age groups, admission was significantly more common for patients who were delayed as a result of the conflict (32\%) than for those who were not $(13 \% ; \mathrm{P}<0.0001)$. In Nablus, which is burdened with the most severe closures, $34 \%$ of the emergency department contacts who experienced conflict related delay were admitted compared with $12 \%$ of those who were not delayed. In Bethlehem, $27 \%$ of the delayed contacts and $15 \%$ of the non-delayed contacts were admitted (table).

The median speed of the patients who were not delayed was 18.0 (range $0.7-120$ ) $\mathrm{km} / \mathrm{h}$, whereas it was $15.5(0.3-90) \mathrm{km} / \mathrm{h}$ for those delayed by the conflict and $12.0(2.7-48) \mathrm{km} / \mathrm{h}$ for those delayed by other reasons. The patients delayed by the conflict had generally travelled a greater distance than the others.

\section{Discussion}

Although we collected data during a relatively calm period in the West Bank, 394 of the 2228 emergency department contacts reported being delayed at checkpoints or by detours on their way to hospital, and they were more likely to be admitted to hospital than were non-delayed patients. One possible explanation for this is that people who have to pass checkpoints live at a greater distance from the hospital. The need to pass a checkpoint might discourage sick people from seeking medical care for fear of being denied access or held back. When they eventually do seek help, their condition has deteriorated and admission is needed. Our study might have underestimated the health consequences of movement restrictions in the West Bank, as it did not include data about people who were completely denied access to emergency departments.

The West Bank closure system comprises more than 600 physical barriers placed on roads by the Israeli army to restrict Palestinian traffic. Most of these checkpoints are placed within the occupied territories and do not restrict the interaction between Israelis and Palestinians, but rather between Palestinians and Palestinians. $^{2}$

The UN Bertini mission in 2002 obtained a commitment from Israeli authorities to clear ambulances at checkpoints within 30 minutes. ${ }^{3}$ The Red Crescent uses this definition when reporting delay of ambulances. ${ }^{4}$ In our study, we did not specify the delay 
in terms of time, as we assumed that quantification of their delay by patients would be too inaccurate. Additionally, defining a level of "acceptable delay" makes no sense from a medical point of view.

The Geneva Convention of 1949 and the additional protocols of 1977 mandate the right to access to medical care for civilians under occupation. The reported delay in access to healthcare facilities is not in accordance with these principles.

Contributors: All authors conceived the study. MJHR and A-LK collected the data. All authors contributed to data analyses and interpretation, wrote the manuscript, and contributed to the revision.
Funding: The Plum Foundation.

Competing interests: None declared.

1 Krug EG, Mercy JA, Dahlberg LL, Zwi AB. The world report on violence and health, WHO. Lancet 2002;360:1083-8.

Lenin Y, Eran S, Raz E. Forbidden road:Israel's discriminatory road regime in the West Bank 2004. Jerusalem: Btselem, 2004.

3 Bertini C. Mission report: 11-19 August 2002. UN Secretary General. Available at: htpp://domino.un.org.bertini_rpt.htm.

4 Palestine Red Crescent Society. PRCS weekly press release for the period 31 December 2005-06 January 2006. Available at: www.palestinercs.org/ pressreleases/Year\%0202006/pr070106wbrr.htm.

(Accepted 1 March 2006)

doi 10.1136/bmj.38793.695081.AE

\title{
Potential for organ donation in the United Kingdom: audit of intensive care records
}

\author{
Kerri Barber, Sue Falvey, Claire Hamilton, Dave Collett, Chris Rudge
}

UK Transplant,

NHS Blood and

Transplant, Bristol

BS34 8RR

Kerri Barber

principal statistician

Sue Falvey

director of donor care

and coordination

Claire Hamilton

senior statistician

Dave Collett

director of statistic.

and audit

Chris Rudge

managing and

transplant director

Correspondence to:

C Rudge

chris.rudge@

uktransplant.nhs.uk

BMJ 2006;332:1124-6

\begin{abstract}
Objectives To determine the true potential for solid organ donation from deceased heartbeating donors and the reasons for non-donation from potential donors.

Design An audit of all deaths in intensive care units, 1 April 2003 to 31 March 2005. The study was hierarchic, in that information was sought on whether or not brain stem testing was carried out; if so, whether or not organ donation was considered; if so whether or not the next of kin were approached; if so, whether or not consent was given; if so, whether or not organ donation took place.

Setting 341 intensive care units in 284 hospitals in the United Kingdom.

Participants 46801 dead patients, leading to 2740 potential heartbeating solid organ donors and 1244 actual donors.
\end{abstract}

Main outcome measures Proportion of potential deceased heartbeating donors considered for organ donation, proportion of families who denied consent, and proportion of potential donors who became organ donors.

Results Over the two years of the study, $41 \%$ of the families of potential donors denied consent. The refusal rate for families of potential donors from ethnic minorities was twice that for white potential donors, but the age and sex of the potential donor did not affect the refusal rate. In $15 \%$ of families of potential donors there was no record of the next of kin being approached for permission for organ donation.

Conclusions Intensive care units are extremely good in considering possible organ donation from suitable patients. The biggest obstacle to improving the organ donation rate is the high proportion of relatives who deny consent.

\section{Introduction}

The United Kingdom has a serious shortage of organs for transplantation, as does almost every country. The number of deceased heartbeating donors has remained relatively static since 1998, ranging from 644 to 739 donors a year, having fallen from a peak of 923 in $1989 .{ }^{12}$ The heartbeating donor rate in 2004 was 12.3 per million population, which is one of the lowest rates in western Europe. Spain has an exceptional rate of 33.0 per million population, but most other countries in Europe have rates between 13 and 22 per million population (see bmj.com). ${ }^{3}$

Only one systematic study has been performed of the potential for organ donation from intensive care units, which was carried out in 1989-90 and was restricted to England and Wales. ${ }^{4}$ This estimated that in 1200-1350 patients a year death was diagnosed after brain stem tests and that half of these patients became actual organ donors. It also reported that, when approached, $30 \%$ of relatives of potential donors refused consent for organ donation, though differences in methods prevent direct comparisons with our study.

UK Transplant was established in 2000 with a specific responsibility to introduce measures to increase organ donation. As part of this process a national potential donor audit was developed to identify the true potential for organ donation from dead donors, together with the reasons for non-donation. We describe the establishment and implementation of the potential donor audit together with the overall results from the first two years for potential heartbeating donors.

\section{Methods}

The potential donor audit was designed on a hierarchical basis. Basic demographic information (not

$$
\text { The audit form is on bmj.com. }
$$

This is the abridged version of an article that was posted on bmj.38804.658183.55 